\title{
Relações entre concepções sobre a natureza do conhecimento matemático, propostas didáticas e concepções de ensino em dissertações em Educação Matemática do PPGEDUCEM da PUCRS
}

\author{
Relations between conceptions of the nature of mathematical \\ knowledge, didactic proposals and teaching's conceptions in \\ Mathematics Education's dissertations from PPGEDUCEM of PUCRS
}

Luciano Sant'Ana Agne

lucianoagne@yahoo.com.br

\begin{abstract}
Resumo
O presente trabalho investigou as relações entre as concepções sobre a natureza do conhecimento matemático, as propostas didáticas e as concepções de ensino em pesquisas de mestrado em Educação Matemática. Foram escolhidas dissertações nas quais os alunos realizaram pesquisa em sala de aula apoiadas no princípio teórico Educar Pela Pesquisa. Treze dissertações de mestrado do programa de Pósgraduação em Educação em Ciências e Matemática da PUCRS foram analisadas. A investigação teve abordagem qualitativa interpretativa. Para análise das informações foi utilizado o método da Análise Textual Discursiva. Três dimensões foram consideradas nesta análise: as propostas didáticas empregadas nas atividades em sala de aula, as concepções sobre a natureza do conhecimento matemático e as concepções sobre ensino implícitas. As concepções de ensino foram analisadas segundo os pressupostos do Educar Pela Pesquisa. Os resultados revelaram que apesar das dissertações adotarem este princípio teórico em suas argumentações explícitas, existem algumas dificuldades de compreensão e aplicação das relações teóricas. Também foi constatado que, mesmo defendendo propostas pedagógicas fundamentadas em pesquisa em sala de aula, as pesquisas investigadas apresentam uma concepção absolutista acerca da natureza do conhecimento matemático.
\end{abstract}

Palavras-chave: Concepção matemática. Concepções de ensino. Educar pela Pesquisa. Propostas didáticas.

\footnotetext{
Abstract

This study has analysed the connections between the conceptions about the nature of mathematical knowledge, teaching plans and the conceptions about teaching found in Masters in Mathematical Education researches. Studies which featured classroom research based on the theory of Education Through Research were selected. Thirteen Master's dissertations from the PUCRS Master Degree Program in Science and Mathematics Education have been analyzed through a qualitative and interpretive approach. The Discoursive Textual Analysis was used to data analysis. Three aspects were considered:
} 
teaching plans used in classroom activities, conceptions of the nature of mathematical knowledge, and the underlying conceptions of teaching. The conceptions of teaching were analyzed according to the assumptions of Teach For Search. The results show that despite dissertations adopt the theory of through research in their arguments, there are some difficulties in understanding and applying the theoretical. It was also noticed that, despite the use of teaching plans based on research in the classroom, the studies analyzed show an absolutistic conception of mathematical knowledge.

Keywords: Conception of math. Conceptions of teaching. Education Through Research. Teaching plans.

\section{Introdução}

O propósito desta pesquisa foi compreender quais concepções fundamentam as propostas pedagógicas em que os alunos desenvolvem pesquisa em sala de aula. A partir dessa proposta, surgiu a seguinte questão de pesquisa: quais as relações entre propostas didáticas, concepções de ensino e concepções sobre a natureza do conhecimento matemático em dissertações sobre Educação Matemática do PPGEDUCEM - PUCRS que utilizam como princípio teórico o Educar Pela Pesquisa?

Para alcançar este intento investigamos no âmbito do Programa de Pós-graduação em Educação em Ciências e Matemática (PPGEDUCEM) da PUCRS e encontramos trabalhos valiosos e muito bem elaborados. Ao final escolhemos treze que assumem como princípio teórico o Educar Pela Pesquisa, com os sujeitos realizando investigações em seu ambiente de aprendizagem, ou seja, o aluno fazendo pesquisa para aprender Matemática.

Todas as dissertações investigadas afirmam que é necessário o desenvolvimento de alternativas para que o ensino de matemática seja mais proveitoso e produtivo. Nesta perspectiva, aliamo-nos com Ramos, Lima e Rocha $\mathrm{F}^{\mathrm{o}}$ (2009, p.53) que afirmam que o trabalho em sala de aula fundamentado na pesquisa "nas disciplinas de Ciências e Matemática, contribuem para a qualificação do ensino e ampliam as possibilidades de aprendizagem nessas disciplinas".

Este artigo foi redigido utilizando os dados e resultados obtidos na pesquisa de mestrado realizada pelo autor.

Nesta pesquisa considerei o princípio teórico conhecido como Educar Pela Pesquisa (doravante tratado pela sigla EPP), semelhante ao Modelo Didático Investigativo de Pórlan (1993). Ambas as teorias convergem em pontos importantes. 


\title{
2. O Educar Pela Pesquisa (EPP)
}

Tanto no princípio teórico do EPP, conforme Moraes e Lima (2004), quanto no modelo didático fundamentado na investigação em sala de aula, conforme Porlán (1993), as concepções prévias dos educandos são fatores fundamentais e determinantes da sequencia de atividades a serem desenvolvidas em sala de aula. Ramos, Lima e Rocha $\mathrm{F}^{\mathrm{o}}$ (2009, p. 56) afirmam que nesse modelo "o estudante é protagonista de suas aprendizagens, superando as concepções tradicionais de ensino e de aprendizagem”.

Nesta perspectiva, Porlán (1993) sustenta que os educadores devem primeiramente fazer um levantamento para saber quais são as concepções prévias e os conhecimentos escolares prévios dos alunos, para assumir o papel de facilitadores do processo de ensino e aprendizagem. A partir desse entendimento a prática investigativa em sala de aula assume grande potencialidade didática, pois todo o conhecimento a ser gerado e construído na escola passa a ter uma postura epistemológica própria. Isso implica na análise de diferentes tipos de informação, ou seja, buscar essas informações em diferentes áreas do conhecimento potencializando a investigação com olhar crítico sobre as questões estudadas.

A proposta pedagógica do EPP possui quatro pressupostos fundamentais:

\begin{abstract}
A convicção de que o educar pela pesquisa é a especificidade mais própria da educação escolar e acadêmica; $\mathrm{O}$ reconhecimento de que o questionamento reconstrutivo com qualidade formal e política é o cerne do processo de pesquisa; A necessidade de fazer da pesquisa atitude cotidiana no professor e no aluno; A definição de educação como processo de formação da competência histórica humana (DEMO, 2011, p.7).
\end{abstract}

Quando o ambiente escolar se torna um lugar de investigação, os sujeitos participantes desse processo constroem conhecimentos, estabelecem um ambiente de respeito e diálogo e fortalecem os valores formadores do ser humano historicamente constituído, exercitando assim a cidadania plena. A educação escolar se diferencia dos outros espaços educacionais justamente pela oportunidade de se construir conhecimento pela pesquisa. Este ambiente tem a capacidade de proporcionar a interação entre teorias científicas com a prática contextualizada criando a possibilidade de reconstrução e (re)significação de conceitos e ideias (DEMO, 2011).

Demo (2011) ainda afirma que o EPP consagra a capacidade do aluno em questionar o meio em que vive e a sua realidade, proporcionando a ele a decisão de mudar ou não o 
seu contexto social. É o que este autor define como a qualidade formal e política da educação. Formal pela bagagem de conhecimento científico adquirida na escola e política pelo desenvolvimento do questionamento reconstrutivo do aluno.

Educar pela Pesquisa é, portanto, imprimir qualidade formal e política à aprendizagem. É estruturar o trabalho pedagógico de modo a propiciar a formação de um sujeito com autonomia para aprender, com disposição para solucionar problemas, num processo que visa, ainda, amadurecer os aspectos crítico, ético e cooperativo de um sujeito que reivindicará participação política, na luta pela qualificação da vida tanto no sentido individual quanto coletivo. Nesse sentido, a pesquisa na sala de aula concretiza-se por meio do questionamento reconstrutivo, da reconstrução de $\operatorname{argumentos} \mathrm{e}$ da comunicação e validação desses argumentos (RAMOS, LIMA e ROCHA F ${ }^{\circ}$, 2009, p. 56).

Conforme Porlán (1993), o desenvolvimento do "pensamento reflexivo e autônomo" se define como a principal finalidade da educação escolar. Esse pensamento reflexivo tem o papel de mediador entre o conhecimento cotidiano e o conhecimento científico. Porém, a reflexão por si só não é suficiente, pois requer uma reconstrução e (re)significação crítica das teorias científicas a partir da sua aplicação no cotidiano dos alunos.

Seguindo o pressuposto de que o processo de ensino e aprendizagem na proposta do EPP se inicia pelos questionamentos dos alunos, conforme Moraes e Lima (2004), a linguagem adotada é fundamental para que se estabeleçam as relações lógicas entre o conhecimento científico e as concepções prévias dos alunos.

Os estudantes reconstroem os seus argumentos, pois partem do que já conhecem. Não há como aprender algo sobre o que não se conhece o mínimo que possibilite estabelecer relações lógicas. Por isso, só se aprende o que já se sabe. Dito de outro modo, só é possível aprender o que pode estabelecer relação com o conhecimento que já se tem. Isso está intimamente relacionado com a própria linguagem que se construiu e com a qual se pode operar (RAMOS, LIMA e ROCHA F ${ }^{\circ}$, 2009, p. 58).

Pórlan (1993) argumenta que a perspectiva da pesquisa em sala de aula centrada na escola, como postura própria da instituição, pode proporcionar uma transformação progressiva dos processos de ensino e da própria sociedade. Esta condição só se sustenta se o professor assumir uma postura de investigação e reflexão crítica na sua prática diária. Para isso, conforme Demo (2011), o professor deve atualizar e melhorar seu projeto pedagógico constantemente, produzindo e reelaborando conhecimentos de acordo com os desafios que encontra no seu dia a dia. Segundo esse autor, este processo 
proporciona ao educador a reconstrução constante de uma teoria crítica para a educação e tem a capacidade de melhorar todo o processo educativo escolar.

Neste sentido, o papel do professor é fundamental na proposta do EPP. Ele é o grande coordenador das atividades. Aquele que disponibiliza condições para que a aprendizagem aconteça efetivamente. Para Demo (2011) o professor, ao assumir a postura de pesquisador, não pretende que sejam criados conhecimentos científicos novos, mas propõe e cria condições para que os alunos reconstruam e (re)siginifiquem os conceitos científicos já existentes, contextualizando-os em sua realidade.

Conforme Demo (2011), a proposta pedagógica do EPP consiste numa postura que envolve todos os sujeitos do processo educativo e impacta diretamente na sociedade. Nesta perspectiva os alunos e os professores se envolvem diretamente numa ação afirmativa e inovadora de educação, questionando a realidade, argumentando sobre fatos e fenômenos, reconstruindo significados e propondo ações alternativas aos problemas encontrados.

\section{Metodologia}

Esta pesquisa consistiu no estudo de treze dissertações de mestrado aprovadas no âmbito do Programa de Pós-Graduação em Educação em Ciências e Matemática da Pontifícia Universidade Católica do Rio Grande do Sul no período de 2004 a junho de 2012. Esta investigação teve abordagem qualitativa interpretativa conforme propõem Lüdke e André (1986), Bogdan e Bicklen (1994) e Serrano (1998 e 2007).

No início da investigação foram identificadas um total de 224 dissertações elaboradas no período de 2004 a junho de 2012. Destas, 95 tratavam de Educação Matemática, das quais 56 foram elaboradas a partir de trabalhos desenvolvidos em sala de aula com alunos. Finalmente, foram selecionadas treze dissertações que tinham como objeto a pesquisa em sala de aula realizada pelos alunos e desenvolveram suas investigações apoiadas no princípio teórico do EPP.

Em sequência, foram realizadas leituras das dissertações selecionadas com a finalidade de organizar o material. Logo após, foi elaborada uma planilha contendo as informações gerais de cada dissertação. Destes dados emergiram as dimensões relevantes para esta pesquisa: concepção de ensino de Matemática por meio de pesquisa, concepção sobre a 
natureza do conhecimento matemático e a proposta didática para as atividades realizadas em sala.

Estas dimensões foram analisadas e categorizadas pelo processo da Análise Textual Discursiva, conforme Moraes e Galiazzi (2011). Este método tem início pela unitarização e desmontagem dos textos para a obtenção de unidades com significado, relevantes para o estudo que está sendo feito. Essas unidades com significado são organizadas e codificadas para, logo após serem organizadas em categorias com conteúdos semelhantes. Essas categorias são consideradas intermediárias, pois serão reorganizadas em categorias mais abrangentes. Desse processo surgem as categorias finais sobre as quais são escritos metatextos que as descrevem. Esses metatextos são utilizados para a redação do texto final de análise (MORAES; GALIAZZI, 2011).

\section{Categorias de análise}

As categorias de análise, que surgiram no processo de Análise Textual Discursiva, são apresentadas a seguir e caracterizam as três dimensões investigadas neste trabalho.

As propostas didáticas apresentam como categorias: atividades experimentais, estudo teórico, modelagem na educação e pesquisa de campo. As concepções sobre a natureza do conhecimento matemático dos autores das dissertações investigadas apresentam as categorias: ferramenta e descoberta. E as concepções de ensino defendidas pelos pesquisadores em suas dissertações são: contextualização, estratégia, linguagem, questionamento e ensino significativo.

\subsection{Propostas didáticas}

As atividades desenvolvidas pelos alunos em sala de aula demonstraram as diferentes propostas didáticas utilizadas pelos autores das dissertações investigadas e denotam a diversidade de entendimentos destes ao conceberem tais atividades.

O Quadro 1 mostra as categorias de análise das propostas didáticas. 
Quadro 1 - Categorias das propostas didáticas

\begin{tabular}{|c|c|}
\hline Dissertações (por autor/ano) & Categorias das propostas didáticas \\
\hline Camargo (2004) & Estudo teórico \\
\hline Soares (2005) & Estudo teórico \\
\hline Nina (2005) & Modelagem na educação \\
\hline Ficagna (2005) & Pesquisa de campo \\
\hline Toni (2006) & Pesquisa de campo \\
\hline Altenhofen (2008) & Pesquisa de campo \\
\hline Boesing (2009) & Pesquisa de campo \\
\hline Marmitt (2009) & Estudo teórico \\
\hline Lipp (2009) & Pesquisa de campo \\
\hline Diedrich (2009) & Estudo teórico \\
\hline Júnior (2010) & Atividades experimentais \\
\hline Molon (2011) & Atividades experimentais \\
\hline Cunha (2012) & Estudo teórico \\
\hline
\end{tabular}

Neste trabalho não nos ocupamos da descrição pormenorizada das atividades constantes das propostas didáticas, apenas da caracterização e posterior análise das concepções dos seus autores, como apresentamos a seguir.

\section{Atividades Experimentais}

Na categoria denominada Atividades Experimentais, os alunos construíram retas, triângulos e figuras geométricas, realizaram medidas e montaram experimentos em laboratório. Os conceitos matemáticos foram construídos pelos alunos a partir do seu conhecimento escolar prévio. Em todos os trabalhos pertencentes a essa categoria, as atividades desenvolvidas em sala de aula tinham como principal característica a investigação de conceitos matemáticos a partir do estudo e da observação de objetos.

\footnotetext{
Após análise dos questionários do Pré-teste chegou-se à conclusão de que era necessário aprofundar os conhecimentos de Geometria Plana optando-se, para tal, pela elaboração, conforme escolha dos alunos, de duas Unidades de Aprendizagem: a confecção da camiseta, pois os alunos estavam próximos da formatura no ensino fundamental, e pela construção de uma maquete, lembrando a casa própria (MOLON, 2011, p. 35).
}

\section{Estudo Teórico}

Nesta categoria, as atividades desenvolvidas em sala de aula sempre partiram da pesquisa sobre os conceitos matemáticos envolvidos no trabalho. Os alunos apoiavam suas investigações em estudos sistemáticos e em busca de informações na internet. 
Esses estudos tinham a finalidade de aplicar conceitos matemáticos a problemas e desenvolver o raciocínio lógico dos alunos por meio da investigação de técnicas e algoritmos matemáticos.

O desenvolvimento de atividades com o apoio de softwares foi muito presente nessa categoria. O estudo e a investigação de técnicas de resolução de problemas com a utilização de softwares foi entendido pelos pesquisadores como uma forma importante de preparação dos alunos para o mercado de trabalho.

\begin{abstract}
Um dos interesses na utilização de um software em ambiente educacional é, além de promover a aprendizagem dos conteúdos regulares, proporcionar aos alunos a manipulação de uma ferramenta que lhe seja útil futuramente, principalmente quando estes forem em busca de uma colocação no mercado de trabalho. A planilha possui recursos que contemplam a exploração de conteúdos matemáticos diversos e, sobretudo, possibilita ao aluno o acesso a um software que o qualifica profissionalmente (CUNHA, 2012, p. 31).
\end{abstract}

\title{
Modelagem na Educação
}

Na categoria denominada Modelagem na Educação houve o envolvimento do professor pesquisador e dos alunos no desenvolvimento das investigações. O planejamento das atividades sempre iniciava pelo debate em sala de aula para a busca de assuntos que fossem de interesse dos alunos e que fizessem parte do seu cotidiano. Porém, sempre prevaleciam as escolhas do pesquisador que determinava os assuntos que mais se adequassem aos conteúdos matemáticos que ele pretendia trabalhar com os alunos.

\begin{abstract}
Embora as experiências dos alunos sejam falhas e fragmentadas, o diálogo com o professor lhes permite identificar assuntos importantes para o processo educacional. [...] O segundo obstáculo foi definir o problema, ou seja, o que estudar dentro do tema escolhido. Neste momento, é muito importante a presença do professor para direcionar o trabalho, caso contrário, os alunos podem pesquisar elementos que não levam a um modelo matemático. $\mathrm{O}$ objetivo foi responder a uma pergunta ou dúvida dentro do tema escolhido, por meio da Matemática (NINA, 2005, p. 87).
\end{abstract}

\section{Pesquisa de campo}

Em todas as dissertações que foram categorizadas como Pesquisa de Campo os alunos realizaram investigações fora da sala de aula, entrevistando pessoas ou buscando a compreensão de fenômenos sociais. Neste processo de pesquisa, os alunos constataram posteriormente, sempre com a intervenção do professor pesquisador, as relações matemáticas existentes. 
Sugeri aos alunos que realizassem uma pesquisa com um grupo de 100 pessoas com a seguinte pergunta: "Qual seleção você acha que vai ganhar a Copa de 2006?". Os alunos mostraram-se bastante entusiasmados com a proposta, já que o assunto era de interesse geral e todos estavam ansiosos em saber se a maioria compartilhava das suas opiniões. [...] As pessoas entrevistadas eram vizinhos, colegas, familiares e os alunos combinaram os locais em que entrevistariam as pessoas para não haver coincidência de entrevistados. Entrevistaram as cem pessoas e registraram seus resultados e comentários num formulário. Um dos objetivos desta pesquisa foi compreender o conceito de porcentagem através de frações. Os alunos organizaram as respostas em forma fracionária e desta maneira, encontraram as frações de denominador cem (ALTENHOFEN, 2008, p. 51).

Este processo valorizou as concepções prévias dos alunos e o seu contexto social, pois as questões investigadas foram definidas pelos próprios alunos, sujeitos desses trabalhos. A Matemática serviu como instrumento para caracterizar e descrever os resultados.

\subsection{Concepções sobre a natureza do conhecimento matemático}

Nesta seção apresentamos as categorias da concepção sobre a natureza do conhecimento matemático dos autores das dissertações.

Nas atividades propostas aos alunos pelos pesquisadores das dissertações investigadas, as atividades desenvolvidas revelaram as concepções sobre a natureza do conhecimento matemático dos autores destas pesquisas. Estas concepções implícitas nem sempre são congruentes com a argumentação explícita destes autores sobre como os alunos devem aprender Matemática. Estas concepções foram agrupadas em duas categorias: Descoberta e Ferramenta, conforme o Quadro 2.

Quadro 2 - Categoria das concepções sobre a natureza do conhecimento matemático

\begin{tabular}{|c|c|}
\hline Dissertações (por autor/ano) & $\begin{array}{c}\text { Categoria das concepções sobre a natureza do conhecimento } \\
\text { matemático }\end{array}$ \\
\hline Camargo (2004) & Descoberta \\
\hline Nina (2005) & Descoberta \\
\hline Soares (2005) & Ferramenta \\
\hline Ficagna (2005) & Ferramenta \\
\hline Toni (2006) & Ferramenta \\
\hline Altenhofen (2008) & Ferramenta \\
\hline Boesing (2009) & Ferramenta \\
\hline Marmitt (2009) & Ferramenta \\
\hline Lipp (2009) & Ferramenta \\
\hline Diedrich (2009) & Ferramenta \\
\hline Júnior (2010) & Ferramenta \\
\hline Molon (2011) & Ferramenta \\
\hline Cunha (2012) & Ferramenta \\
\hline
\end{tabular}




\section{Descoberta}

Segundo Fernandes, Luft e Guimarães (1996) descobrir algo significa revelar o que já existe, o que está escondido, encontrar pela primeira vez. É com este sentido que as atividades matemáticas são desenvolvidas nas dissertações que apresentam esta concepção. Esta categoria se caracteriza por um forte caráter de constatação da Matemática existente nos fenômenos e objetos observáveis.

Com o forte caráter de desenvolvimento do raciocínio lógico das atividades, os autores das dissertações concebiam os conceitos matemáticos como verdades absolutas passíveis de serem reveladas no processo de investigação em sala de aula.

Apenas duas dissertações apresentaram esta concepção matemática em seus trabalhos: Camargo (2004) e Nina (2005). A dissertação de Camargo (2009) desenvolveu suas atividades de sala de aula buscando a contextualização dos conceitos matemáticos. Neste caso os alunos deveriam descobrir as relações matemáticas implícitas nos objetos investigados. A dissertação de Nina (2005) desenvolveu estratégias de solução de problemas que revelassem os conceitos matemáticos existentes nos fenômenos abordados no processo de investigação em sala de aula.

\section{Ferramenta}

Nesta categoria, que abrange todas as outras onze dissertações investigadas, a Matemática é concebida como uma ferramenta para descrever o mundo e solucionar seus desafios. Para os autores das dissertações, a Matemática é composta de um conjunto de sinais com significado que se relacionam entre si. Ela é considerada um poderoso instrumento para dar significado aos fenômenos e objetos, podendo contextualizá-los ou não.

Neste caso, a Matemática dos livros didáticos é considerada verdade absoluta e impossível de ser modificada, apenas utilizada. Seus conceitos são definitivos, não podem ser mudados ou (re)significados.

\subsection{Concepções de ensino}

Nesta seção são apresentadas as categorias das concepções de ensino subjacentes às dissertações estudadas e que emergiram no processo de análise, ou seja, as concepções 
de ensino de Matemática por meio de pesquisa dos autores das dissertações. As categorias são: Contextualização, Estratégia, Linguagem, Questionamento e Ensino Significativo.

O Quadro 3 mostra a relação das dissertações com as categorias de concepção de ensino.

Quadro 3 - Categorias das concepções de ensino

\begin{tabular}{|c|c|}
\hline Dissertações (por autor/ano) & Categorias das concepções de ensino \\
\hline Camargo (2004) & Contextualização \\
\hline Soares (2005) & Linguagem \\
\hline Nina (2005) & Estratégia \\
\hline Ficagna (2005) & Contextualização \\
\hline Toni (2006) & Questionamento \\
\hline Altenhofen (2008) & Contextualização \\
\hline Boesing (2009) & Estratégia \\
\hline Marmitt (2009) & Ensino significativo \\
\hline Lipp (2009) & Contextualização \\
\hline Diedrich (2009) & Ensino significativo \\
\hline Júnior (2010) & Linguagem \\
\hline Molon (2011) & Ensino significativo \\
\hline Cunha (2012) & Ensino significativo \\
\hline
\end{tabular}

\section{Contextualização}

O sentido da categoria Contextualização aparece nas dissertações como sendo uma maneira de relacionar o conhecimento matemático com os fenômenos e objetos acessíveis ao entendimento e a realidade dos alunos. Estes fenômenos e objetos fazem parte do cotidiano dos alunos ou pelo menos estão presentes de alguma forma na vida deles, porém sem que tenham uma relação com o conhecimento científico.

Nas dissertações estudadas, contextualizar o ensino de Matemática significa identificar e relacionar os conceitos matemáticos com fenômenos e objetos da experiência dos alunos. Significa colocar os alunos em contato com alguma coisa, fenômeno ou objeto, e desta ação, que é premeditada pelo professor pesquisador, decorre que o indivíduo, sujeito da investigação, se situa no tempo e no espaço desejado.

Estas dissertações afirmam que a aprendizagem matemática realizada de maneira contextualizada proporciona aos alunos o desenvolvimento do pensamento crítico e de competências para a resolução de problemas. Dessa forma o aluno desenvolve a capacidade de resolver problemas no contexto da sua vida social, principalmente frente aos desafios do mundo produtivo. Isso também desenvolve um cidadão critico e reflexivo capaz de modificar a realidade em que vive. 
Um pensar crítico é essencial para a realização de um trabalho em equipe, para a resolução de problemas, bem como para a tomada de decisões de forma eficaz e eficiente, baseada em argumentos suportados por razões convincentes. Assim, passa a ser consensual a idéia de que o êxito de qualquer sistema democrático depende da capacidade de os indivíduos atuarem e intervirem, usando seu potencial de pensamento crítico (Lipp, 2009, p. 24).

\section{Estratégia}

Esta categoria é concebida nas dissertações analisadas como um modelo pedagógico que, por meio de pesquisa em sala de aula, promove o desenvolvimento de idéias para a resolução de problemas.

As dissertações dessa categoria defendem que, na realidade da vida cotidiana dos alunos, é comum que eles tenham que enfrentar diversas situações que exigem posicionamentos críticos e reflexivos. Nesta perspectiva, o ensino fundamentado em estratégias para a resolução de problemas atende à necessidade de enfrentamento crítico da realidade. Boesing (2009, p. 37) afirma que "os processos de ensino e de aprendizagem da Matemática por meio da investigação são vistos de forma vinculada à resolução de problemas". Isso pressupõe desenvolver a autonomia e o pensamento crítico para que os alunos utilizem os seus conhecimentos matemáticos para resolver os desafios que surgem na sua vida, ou seja, "a autonomia e o pensamento crítico, são características que são desenvolvidas em práticas que valorizam o aluno como sujeito, a exemplo da prática da pesquisa em sala de aula" (p.67).

\section{Linguagem}

Nesta categoria, as dissertações defendem que a linguagem é um instrumento de expressão do pensamento e que o ensino de Matemática se fundamenta nas atividades intelectuais dos alunos. "As representações, as crenças e as concepções em torno da Matemática revelam-na como uma linguagem simbólica, que se expressa com notações formais, definida de forma abstrata" (SOARES, 2005, p. 43).

Neste sentido, depreende-se que é necessário que o educador observe a capacidade de raciocínio e de expressão das ideias dos educandos, criando condições que permitam o aperfeiçoamento desse raciocínio. O professor relaciona conteúdo matemático, 
metodologia de ensino e processos cognitivos com a capacidade do aluno de se expressar por meio da linguagem.

\section{Questionamento}

Nesta categoria se considera que o questionamento dos alunos facilita a aprendizagem Matemática, pois revela os conhecimentos escolares prévios trazidos por eles quando se deparam com uma situação a ser investigada.

\footnotetext{
É preciso superar a aula que dá enfoque à memorização de fórmulas (aprendizagem mecânica) e enfatizar as aulas que provoquem questionamentos, interagindo com o aluno para que ele consiga estabelecer relações entre conceitos aprendidos, e buscar a aprendizagem (TONI, 2006, p. 31).
}

Ao analisar esta dissertação, depreende-se que o questionamento é o primeiro passo assumido pelos alunos para iniciar o processo de pesquisa em sala de aula. Para o pesquisador, este processo desenvolve a capacidade do aluno de estabelecer relações entre o mundo real e as teorias que o descrevem, melhora sua capacidade de observação e entendimento de fenômenos e objetos que integram a realidade que lhe cerca. Isto também leva o aluno a aumentar o nível de complexidade dos conceitos que aprende.

Segundo defende o autor dessa dissertação, o questionamento está relacionado diretamente com a postura de investigação, para a construção e reconstrução do conhecimento, pois estabelece uma via de mão dupla entre a pergunta e a busca pela resposta. A postura de questionador do professor é, também, uma poderosa ferramenta de motivação e incentivo à curiosidade científica no aluno, em função da constante construção de desafios que ele enfrenta e deve solucionar.

\section{Ensino Significativo}

Esta categoria defende o ensino significativo da Matemática por meio da Teoria da Aprendizagem Significativa, de David Ausubel. As dissertações investigadas afirmam que a pesquisa em sala de aula torna os fenômenos e objetos matemáticos mais compreensíveis e com significado próprio para os alunos.

Estas dissertações afirmam que a aprendizagem significativa tem duas características fundamentais. A primeira é a relação entre o conteúdo a ser estudado e os 
conhecimentos escolares prévios do aluno. A segunda é que um dos caminhos para a aprendizagem significativa é o EPP em sala de aula ${ }^{1}$.

\begin{abstract}
A teoria da Aprendizagem Significativa, de David Ausubel (...) sugere que os novos conhecimentos construídos estejam relacionados com os conceitos prévios dos alunos, valorizando o que eles já sabem e assim permitindo a construção de estruturas mentais de forma prazerosa. [...] Então, a aprendizagem significativa permite ao aluno expressar suas ideias, seus pensamentos e reflexões, tornando-se um ser participante do desenvolvimento da atividade, provendo interações entre a teoria e prática. Uma forma de se obter uma aprendizagem significativa, destacada por muitos autores, é o "educar pela pesquisa", pois ela visa a uma inovação da prática de sala de aula pela pesquisa e valoriza os conhecimentos prévios dos alunos (MOLON, 2011, p. 17).
\end{abstract}

Após a apresentação das categorias de ensino implícitas nas dissertações investigadas, passamos para a próxima seção em que relacionamos e comentamos as categorias analisadas.

\title{
5. Relacionando categorias e concepções
}

Nesta seção, apresentamos o quadro que mostra as relações entre as categorias e concepções destacadas no processo de análise.

Quadro 4 - Relações entre as categorias de análise

\begin{tabular}{|c|c|c|c|}
\hline $\begin{array}{l}\text { Dissertação } \\
\text { (Por autor) }\end{array}$ & $\begin{array}{c}\text { Categorias das } \\
\text { propostas didáticas }\end{array}$ & $\begin{array}{c}\text { Categorias das } \\
\text { concepções de ensino }\end{array}$ & $\begin{array}{c}\text { Categoria das concepç̃̃es sobre a } \\
\text { natureza do conhecimento } \\
\text { matemático }\end{array}$ \\
\hline Júnior (2010) & \multirow{2}{*}{$\begin{array}{l}\text { Atividades } \\
\text { experimentais }\end{array}$} & Linguagem & \multirow{2}{*}{ Ferramenta } \\
\hline Molon (2011) & & Ensino significativo & \\
\hline Camargo (2004) & \multirow{5}{*}{ Estudo teórico } & Contextualização & Descoberta \\
\hline Soares (2005) & & Linguagem & Ferramenta \\
\hline Marmitt (2009) & & \multirow{3}{*}{ Ensino significativo } & \multirow{3}{*}{ Ferramenta } \\
\hline Diedrich (2009) & & & \\
\hline Cunha (2012) & & & \\
\hline Nina (2005) & $\begin{array}{l}\text { Modelagem na } \\
\text { educação }\end{array}$ & Estratégia & Descoberta \\
\hline Ficagna (2005) & \multirow{5}{*}{ Pesquisa de campo } & & \multirow{5}{*}{ Ferramenta } \\
\hline Lipp (2009) & & Contextualização & \\
\hline Altenhofen (2008) & & & \\
\hline Boesing (2009) & & Estratégia & \\
\hline Toni (2006) & & Questionamento & \\
\hline
\end{tabular}

\footnotetext{
${ }^{1}$ Esta afirmação não foi feita por David Ausubel. A sua teoria não afirma nada sobre investigação em sala de aula ou mesmo sobre EPP.
} 
Observando as relações apresentadas no Quadro 4, percebe-se que as dissertações que defendem o Ensino Significativo e o EPP como princípio teórico, não sustentam uma argumentação coerente com essa relação. No contexto do EPP, conforme Demo (2011), o aluno desenvolve um pensamento reflexivo e autônomo que tem o papel de mediador entre o conhecimento cotidiano e científico. Este processo requer que o aluno não se detenha apenas na reflexão, mas reconstrua e (re)signifique criticamente os conceitos investigados e aprendidos.

No EPP, o professor não define de maneira autoritária quais conteúdos devem ser estudados pelos alunos. O processo pedagógico se inicia pelos questionamentos dos alunos. Nas dissertações categorizadas como Ensino Significativo, o professor define os conteúdos a serem abordados e os temas a serem investigados. O Ensino Significativo tem uma postura absolutista em relação ao ensino de Matemática, pois o professor é o detentor de todo o conhecimento a ser transmitido para o aluno. O questionamento do aluno ocorre somente quando ele tem que contextualizar os conceitos definidos pelo professor.

Nas dissertações categorizadas como Ensino Significativo, predomina como proposta didática o Estudo Teórico, só uma apresenta-se como Atividades Experimentais.

O Quadro 4 mostra que as categorias de análise das propostas didáticas se dividem igualmente entre o Estudo Teórico e a Pesquisa de Campo. Isso denota o entendimento predominante de que realizar pesquisa em sala de aula é coletar dados e analisá-los estatisticamente ou investigar conceitos matemáticos na literatura e na internet. Porém, na dissertação de Camargo (2004), apesar de apresentar como proposta didática o Estudo Teórico, situa-se na categoria Contextualização como concepção de ensino. Para este autor é possível contextualizar o conhecimento obtido nos livros didáticos, mesmo que esse conhecimento seja abordado como verdade absoluta.

A categoria de análise da proposta didática denominada Pesquisa de Campo é mais diversificada na sua relação com as categorias de ensino, pois se relaciona com Contextualização, Estratégia e Questionamento. No entendimento dos pesquisadores destas dissertações, Ficagna (2005), Altenhofen (2008) e Lipp (2009), pesquisa de campo é uma atividade que tem natureza contextualizadora, pois os sujeitos geralmente desenvolvem essas atividades no seu contexto social. 
Boesing (2009) apresenta como proposta didática a Pesquisa de Campo e como concepção de ensino a Estratégia. Isso demonstra que a pesquisa de campo serviu para fornecer dados para problemas matemáticos que foram solucionados por meio de estratégias.

\section{Conclusões}

O objetivo dessa pesquisa foi plenamente atingido, pois foi possível identificar e categorizar as concepções dos autores das pesquisas além de estabelecer relações entre elas.

Como resultado mais relevante dessa pesquisa, constatamos que todos os pesquisadores analisados têm uma concepção absolutista acerca da natureza do conhecimento matemático mesmo defendendo uma proposta pedagógica fundamentada na pesquisa em sala de aula. Porém isso não significa que as ideias defendidas não proporcionem aprendizagem Matemática. Ao contrário, todas relataram a aprendizagem como resultado fundamental de suas investigações.

Também foi possível verificar como são complexas as relações entre concepções e práticas em sala de aula. Apesar das dissertações adotarem o princípio teórico do EPP em suas argumentações explícitas, existem algumas dificuldades de compreensão e aplicação das relações teóricas entre suas propostas didáticas e suas concepções de ensino.

Com isto, parece ser ainda muito difícil estruturar uma proposta teórica ampla e consistente para o EPP. Isso requer muita dedicação e esforço de pesquisa, pois o EPP ainda é um princípio teórico que está em construção e é muito recente no que se refere à história da educação.

\section{Referências}

ALTENHOFEN, M. E. Atividades contextualizadas nas aulas de Matemática para a formação de um cidadão crítico. 2008. 108 f. Dissertação (Mestrado em Educação em Ciências e Matemática) - Faculdade de Física, Pontifícia Universidade Católica do Rio Grande do Sul, Porto Alegre, 2008. 
BOESING, C. A prática da pesquisa nas aulas de Matemática: vivências de professores do ensino fundamental que integram um grupo de estudos. 2009. 108 f. Dissertação (Mestrado em Educação em Ciências e Matemática) - Faculdade de Física, Pontifícia Universidade Católica do Rio Grande do Sul, Porto Alegre, 2009.

BOGDAN, R.; BIKLEN, S. Investigação qualitativa em educação. Portugal: Porto Editora, 1994.

CAMARGO, S. M. N. Ensino com enfoque na pesquisa: repercussões na aprendizagem de trigonometria. 2004.122 f. Dissertação (Mestrado em Educação em Ciências e Matemática) - Faculdade de Física, Pontifícia Universidade Católica do Rio Grande do Sul, Porto Alegre, 2004.

CUNHA, M. L. Contribuições de uma unidade de aprendizagem sobre Estatística com o recurso da planilha. 2012. 93 f. Dissertação (Mestrado em Educação em Ciências e Matemática) - Faculdade de Física, Pontifícia Universidade Católica do Rio Grande do Sul, Porto Alegre, 2012.

DEMO, P. Educar pela pesquisa. 9 ed. Campinas: Autores Associados, 2011. 148p.

DIEDRICH, R. C. Pesquisa escolar em tempos de cibercultura: ensinando Matemática com o auxílio da internet. 2009. 132 f. Dissertação (Mestrado em Educação em Ciências e Matemática) - Faculdade de Física, Pontifícia Universidade Católica do Rio Grande do Sul, Porto Alegre, 2009.

FERNANDES, F.; LUFT, C.; GUIMARÃES, F. Dicionário brasileiro globo. 43 ed. São Paulo: Globo, 1996.

FICAGNA, N. C. Unidade de aprendizagem: uma forma diferenciada de aprender Estatística alicerçada no educar pela pesquisa. 2005. 179 f. Dissertação (Mestrado em Educação em Ciências e Matemática) - Faculdade de Física, Pontifícia Universidade Católica do Rio Grande do Sul, Porto Alegre, 2005.

JÚNIOR, H. A. Estudo do desenvolvimento do pensamento geométrico por alunos surdos por meio do multiplano no ensino fundamental. 2010. 291 f. Dissertação (Mestrado em Educação em Ciências e Matemática) - Faculdade de Física, Pontifícia Universidade Católica do Rio Grande do Sul, Porto Alegre, 2010.

LIPP, T. H. P. Estudo do desenvolvimento de competências críticas e reflexivas a partir de uma unidade de aprendizagem em aulas de Matemática. 2009. 98 f. Dissertação (Mestrado em Educação em Ciências e Matemática) - Faculdade de Física, Pontifícia Universidade Católica do Rio Grande do Sul, Porto Alegre, 2009.

LÜDKE, M.; ANDRÉ, M. E. D. A. Pesquisa em educação: abordagens qualitativas. São Paulo: EPU, 1986.

MARMITT, V. R. Concepções e atitudes em relação à Matemática: maneiras de identificá-las e possibilidades de modificá-las. 2009. 187 f. Dissertação (Mestrado em Educação em Ciências e Matemática) - Faculdade de Física, Pontifícia Universidade Católica do Rio Grande do Sul, Porto Alegre, 2009. 
MOLON, L. As aplicações e contribuições da geometria plana na educação de jovens e adultos no ensino fundamental por meio de unidade de aprendizagem. 2011. $71 \mathrm{f}$. Dissertação (Mestrado em Educação em Ciências e Matemática) - Faculdade de Física, Pontifícia Universidade Católica do Rio Grande do Sul, Porto Alegre, 2011.

MORAES, R. GALIAZZI, M. Análise textual discursiva. 2 ed. Ijuí: Unijuí, 2011.

MORAES, R.; LIMA, V. (Orgs). Pesquisa em sala de aula: tendências para a educação em novos tempos. 2 ed. Porto Alegre: Edipucrs, 2004.

NINA. C. T. D. Modelagem Matemática e novas tecnologias: uma alternativa para a mudança de concepções em Matemática. 2005. 227 f. Dissertação (Mestrado em Educação em Ciências e Matemática) - Faculdade de Física, Pontifícia Universidade Católica do Rio Grande do Sul, Porto Alegre, 2005.

PORLÁN, R. Constructivismo y escuela: hacia un modelo de enseñanza-aprendizaje basado en la investigación. Sevilla: Díada, 1993. 194 p.

RAMOS, M.; LIMA, V.; ROCHA $\mathrm{F}^{\mathrm{o}}$, J. A pesquisa como prática na sala de aula de Ciências e Matemática: um olhar sobre dissertações. Alexandria Revista de Educação em Ciência e Tecnologia, v. 2, n. 3, p. 53-81, nov. 2009.

SERRANO. G. P. Desafios de la investigación cualitativa. $6^{a}$ Conferência. Universidad Nacional de Educación a Distancia (UNED). Chile, Nov, 2007. In: $<$ http://www.rmm.cl/usuarios/pponce/doc/200711151514230.6conferencia_gloria_perez _serrano.pdf $>$. Acesso em set/2011.

SERRANO, G. P. Investigación cualitativa: retos e interrogantes. I. Métodos. Madrid, La Muralla: 1998. 230 p.

SOARES, L. Q. Educar pela pesquisa na pré-escola: a concretude na educação matemática para além do visível e do manipulável. 2005. 154 f. Dissertação (Mestrado em Educação em Ciências e Matemática) - Faculdade de Física, Pontifícia Universidade Católica do Rio Grande do Sul, Porto Alegre, 2005.

TONI, M. P. A compreensão da Estatística a partir da planilha. 2006. $159 \mathrm{f}$. Dissertação (Mestrado em Educação em Ciências e Matemática) - Faculdade de Física, Pontifícia Universidade Católica do Rio Grande do Sul, Porto Alegre, 2006. 